\title{
Catecholamines in the Bed Nucleus of the Stria Terminalis Reciprocally Respond to Reward and Aversion
}

\author{
Jinwoo Park ${ }^{1}$, Robert A. Wheeler, ${ }^{2,3}$, Khristy Fontillas ${ }^{1}$, Richard B. Keithley ${ }^{1}$, Regina M. \\ Carelli $^{2,3}$, and R. Mark Wightman ${ }^{1,3,{ }^{*}}$ \\ ${ }^{1}$ Department of Chemistry, University of North Carolina at Chapel Hill, Chapel Hill, North Carolina \\ 27599-3290, USA \\ ${ }^{2}$ Department of Psychology, University of North Carolina at Chapel Hill, Chapel Hill, North \\ Carolina 27599-3290, USA \\ ${ }^{3}$ Neuroscience Center, University of North Carolina at Chapel Hill, Chapel Hill, North Carolina \\ 27599-3290, USA
}

\begin{abstract}
Background-Traditionally, norepinephrine has been associated with stress responses while dopamine has been associated with reward. Both of these catecholamines are found within the bed nucleus of the stria terminalis (BNST), a brain relay nucleus in the extended amygdala between cortical/limbic centers, and the hypothalamic-pituitary-adrenal axis. Despite this colocalization, little is known about subsecond catecholamine signaling in subregions of the BNST in response to salient stimuli.
\end{abstract}

Methods-Changes in extracellular catecholamine concentration in subregions of the BNST in response to salient stimuli were measured within the rat BNST using fast-scan cyclic voltammetry at carbon-fiber microelectrodes.

Results-A discrete subregional distribution of release events was observed for different catecholamines in this nucleus. In addition, rewarding and aversive tastants evoked inverse patterns of norepinephrine and dopamine release in the BNST. An aversive stimulus, quinine, activated noradrenergic signaling but inhibited dopaminergic signaling, while a palatable stimulus, sucrose, inhibited norepinephrine while causing dopamine release.

Conclusions-This reciprocal relationship, coupled with their different time courses, can provide integration of opposing hedonic states to influence response outputs appropriate for survival.

\section{Keywords}

Norepinephrine; dopamine; dorsolateral bed nucleus of the stria terminalis ( $d$ lBNST); ventral bed nucleus of the stria terminalis ( $\nu$ BNST); fast-scan cyclic voltammetry (FSCV); tastant stimuli

\footnotetext{
(C) 2011 Society of Biological Psychiatry. Published by Elsevier Inc. All rights reserved.

Corresponding author:, R. Mark Wightman, Ph.D., Department of Chemistry, CB \# 3290, Venable Hall, University of North Carolina at Chapel Hill, Chapel Hill, NC, 27599-3290, USA, Tel : +1 (919) 962-1472, Fax : +1 (919) 962-2388, rmw@unc.edu.

Publisher's Disclaimer: This is a PDF file of an unedited manuscript that has been accepted for publication. As a service to our customers we are providing this early version of the manuscript. The manuscript will undergo copyediting, typesetting, and review of the resulting proof before it is published in its final citable form. Please note that during the production process errors may be discovered which could affect the content, and all legal disclaimers that apply to the journal pertain.

All authors have no biomedical financial interests or potential conflicts of interest.

Supplementary materials cited in this article is available online.
} 


\section{Introduction}

It is well established that a group of neuronal circuits form the brain 'reward' pathway, a system that is activated during goal-directed behaviors such as acquisition and consumption of palatable food(1). By analogy, another set of brain circuitry is activated by aversive stimuli and their associated cues(2-4). A portion of both of these systems lies within the extended amygdala, a group of telencephalic nuclei that act as relay centers where information from descending cortical neurons is integrated with limbic afferents to evaluate homeostasis(5). The extended amygdala includes the nucleus accumbens (NAc) shell, a central structure in the brain reward pathway that receives a dense dopaminergic innervation associated with motivation and reward processing(1). Indeed, dopamine release in the NAc is immediately triggered by unexpected reward presentation $(6,7)$ and it is suppressed following delivery of an aversive substance(8).

The extended amygdala also includes the bed nucleus of the stria terminalis (BNST), a catecholamine containing structure that has been linked with negative emotional states and stress $(4,9)$. The BNST consists of more than 12 anatomically distinct subnuclei. It serves as a critical relay center and integrator between limbic structures (e.g. amygdala, hippocampus, and medial prefrontal cortex) and the hypothalamic paraventricular nucleus (PVN)(10). Via these pathways, excitatory and inhibitory input elicited by stress is conveyed to the hypothalamic-pituitary adrenal (HPA) axis $(11,12)$. The anterior BNST receives dense inputs of both norepinephrine and dopamine. The dorsolateral $(d l)$ BNST, that includes the oval nucleus, receives dopaminergic innervation from the ventral tegmental area (VTA), dorsal raphe nucleus and periaqueductal gray area but contains little norepinephrine $(5,13,14)$. It is noteworthy that the function of these dopamine neuron populations in the wake-sleep cycle is different. Recent work suggests that the dopamine neurons in the ventrolateral periaqueductal grey change their activity across sleep-wake periods and promote waking while VTA dopamine neurons do not change its mean firing rate across the sleep-wake cycle $(15,16)$. In contrast to the $d l \mathrm{BNST}$, the ventral $(v)$ BNST, that includes the fusiform nuclei, has a dense noradrenergic innervation from the nucleus of solitary tract (NST), ventrolateral medulla $(\mathrm{VM})$ and locus coeruleus (LC) cell groups, but little dopamine content $(17,18)$. The $(d l)$ and $(v)$ BNST subregions are interconnected with dense projections from the oval nucleus to the fusiform nucleus and a lighter reciprocal connection. The fusiform nucleus has a strong projection to the PVN by which it can activate the HPA axis(10). However, little is known concerning catecholamine neurotransmission within the BNST. While a few stressful stimuli such as fox odor(19) or morphine withdrawal(20) have been shown to evoke norepinephrine increases within the BNST, the large size and slow response of conventional chemical probes has impeded subsecond characterization of behaviorally evoked catecholamine neurotransmission in the subregions of the BNST.

To evaluate brain processing during discrete rewarding and aversive events, we used intraoral delivery of tastants while measuring catecholamine responses with fast-scan cyclic voltammetry at carbon-fiber microelectrodes, a methodology that enables subsecond monitoring of extracellular catecholamines during behavior(21). Animals rapidly differentiate aversive and palatable tastes and show different behavioral outputs(22). Rats exhibit licking behavior during infusions of sucrose, a palatable tastant, and exhibit rejection responses during infusions of quinine, an aversive tastant(23). Since rats typically avoid aversive events, intra-oral deliveries allow evaluation of equal number of rewarding and aversive events detected by the same sensory modality. We used this design to compare in real time the responses to aversive and appetitive stimuli of dopamine and norepinephrine in different subregions of the BNST. 


\section{Materials and Methods}

\section{Animals and Surgery}

Male Sprague-Dawley rats (320-420g, Charles River, Wilmington, MA) were anesthetized with ketamine hydrochloride $(100 \mathrm{mg} / \mathrm{kg})$ and xylazine hydrochloride $(20 \mathrm{mg} / \mathrm{kg})$ and stereotaxic surgeries for electrochemical recordings were performed as described previously(8). Small holes in the skull were drilled for reference $(\mathrm{Ag} / \mathrm{AgCl})$ and stimulating electrodes as well as for carbon-fiber microelectrodes. A guide cannula (Bioanalytical Systems, West Lafayette, IL, USA) for loading a micromanipulator containing a carbonfiber electrode on the day of the experiment was implanted above the $v$ BNST $(0.0 \mathrm{~mm}, 1.2$ $\mathrm{mm}$ lateral from the bregma) or $d l \mathrm{BNST}(0.1 \mathrm{~mm}$ posterior, $1.6 \mathrm{~mm}$ lateral from the bregma)(24). A bipolar, stainless-steel stimulating electrode (Plastics One, Roanoke, VA) was placed in the ventral noradrenergic bundle (VNB) and VTA/substantial nigra(SN) dopaminergic cell bodies (5.2 $\mathrm{mm}$ posterior, $1.0 \mathrm{~mm}$ lateral, $8.0-9.0 \mathrm{~mm}$ ventral). A reference electrode was placed in the contralateral cortex. The implanted items were permanently secured to the skull with dental cement.

Each intra-oral cannula for infusion of sucrose or quinine consisted of an approximately 6 $\mathrm{cm}$ length of PE-100 tubing which was flanged at one end with a Teflon washer(8). The cannulas were inserted lateral to the first maxillary molar with the Teflon washer flush against the molar on each side of the mouth. The other end was accessible via an incision at the top of the head and held in place with a second Teflon washer.

\section{Experimental Design}

One week after recovery from surgery, rats were placed in a standard operant chamber and voltammetric recordings were made. At the start of the behavioral session, white noise was activated to control for potentially interfering ambient noise and the house light was turned on to observe oro-facial responses. After a variable interval (1 to $2 \mathrm{~min}$ ), a peristaltic pump delivered $\sim 200 \mu \mathrm{L}$ of a tastant solution for $3.5 \mathrm{~s}$ through the intra-oral cannula. Rats received multiple trials of sucrose followed by an equal number of trials of quinine at unpredictable times to ensure comparable novelty and salience but opposing hedonic valence. Previous studies showed that this design elicited strong and consistent behavioral differences in hedonic expression with no evidence of anticipatory or conditioned responses(8), and the dopamine response to intra-oral infusions is independent of the order of tastant delivery(8). All animals received a brief rinse with distilled water after each oral infusion to prevent lingering of the prior tastant in subsequent taste reactivity. After the tastant experiments, selective dopamine and norepinephrine drugs were administered to verify that the recorded signal was norepinephrine and/or dopamine. Following pharmacological agents, the tastants were readministered in some animals. Each animal was run only on one day in a single subregion of the BNST.

\section{Voltammetric Procedures}

Glass-encased, cylindrical carbon-fiber microelectrodes with an exposed length of $75-100$ $\mu \mathrm{m}$ T-650 carbon fiber ( $5.1 \mu \mathrm{m}$ in diameter) and reference electrodes were prepared as described previously(25). Fast-scan cyclic voltammetry was computer-controlled. A triangular scan $(-0.4$ to $+1.3 \mathrm{~V}, 400 \mathrm{~V} / \mathrm{s})$ was repeated every $100 \mathrm{~ms}$. Data were digitized and stored on a computer using software written in LABVIEW. Background-subtracted cyclic voltammograms were obtained by digitally subtracting voltammograms collected during stimulation from those collected during baseline recording. Voltammetric responses were viewed as color plots with the abscissa as voltage, the ordinate as acquisition time, and the current encoded in color. As the carbon-fiber microelectrode was used to lesion the brain, thus marking the recording site, this precluded postcalibration of the electrode's 
sensitivity (see below). Instead, we used postcalibration factors per carbon fiber area ( $6.9 \pm$ $0.3 \mathrm{pA} /\left(\mu \mathrm{M} \cdot \mu \mathrm{m}^{2}\right)$ for dopamine, $4.5 \pm 0.2 \mathrm{pA} /\left(\mu \mathrm{M} \cdot \mu \mathrm{m}^{2}\right)$ for norepinephrine) based on the average response obtained from multiple electrodes as described in our previous study(26). Each calibration factor was determined with 5 dopamine and norepinephrine concentration standards. The calibration factors are scaled to the electrode length that varied between 75 $100 \mu \mathrm{m}$. Before the experiment, the length of the exposed carbon fiber was measured.

\section{Histology}

At the end of experiments, the recording sites were verified by electrolytic lesions by applying constant current $(20 \mu \mathrm{A}$ for $10 \mathrm{~s})$ to the carbon-fiber microelectrodes following administration of urethane $(1.2 \mathrm{~g} / \mathrm{kg})(18)$. The animals were subsequently euthanized with an overdose of urethane. Brains were removed and stored in $10 \%$ formaldehyde, and coronally sectioned into $40 \mu \mathrm{m}$ thick slices with a cryostat. The sections mounted on slides were stained with $0.2 \%$ thionin, and coverslipped before viewing under a light microscope.

\section{Drugs and Reagents}

In all animals, at least one drug selective for each catecholamine was administered intraperitoneally(i.p.) to verify that the recorded signal was norepinephrine and/or dopamine after both tastant experiments and their effects on electrically stimulated release were evaluated. All drugs were obtained from Sigma-Aldrich (St. Louis, MO, USA). Desipramine-HCl (15 mg/kg), raclopride- $\mathrm{HCl}(2 \mathrm{mg} / \mathrm{kg})$, and idazoxan- $\mathrm{HCl}(5 \mathrm{mg} / \mathrm{kg})$ were dissolved in saline. GBR $12909(15 \mathrm{mg} / \mathrm{kg})$ was dissolved in water and diluted in saline. The doses of the drugs used are ones that are commonly used in microdialysis studies.

\section{Data Analysis}

The changes of basal catecholamine level by the tastants or electrically evoked catecholamines over time were identified by a locally-written principal component regression algorithm as descried earlier $(27,28)$. A residual analysis procedure was used to verify that the cyclic voltammograms of the trials being predicted were consistent with the analyte cyclic voltammograms used for calibration. Any trials containing uncharacteristic variance larger than $95 \%$ of the noise of the training set were discarded.

Clampfit 8.1 (Axon Instruments, Foster City, CA, USA) was used to analyze half-life $\left(\mathrm{t}_{1 / 2}\right.$, the time to descend from its maximum value to half of that value) as described in the literature(18). Electrically stimulated catecholamine release was recorded every 4 min for 20 min prior to and for $30 \mathrm{~min}$ after intraperitoneally administration of drugs. To determine the catecholamine concentration changes during tastant trials, data from each trial $(-5 \mathrm{~s}$ before and $20 \mathrm{~s}$ after infusion onset) were first background subtracted using the local minima in the $5 \mathrm{~s}$ prior to infusion onset as the baseline. Significant changes over time were evaluated using average baseline ( -5.0 to $0 \mathrm{~s}$ relative to infusion onset) and maximal evoked catecholamine concentration during and after infusion ( 0.1 to $15 \mathrm{~s}$ ). Mean values were compared by using the two-tailed Student's $t$-test to calculate the level of significance. Statistical significance of difference in $t_{ \pm 20 \mathrm{nM}}(\mathrm{s})$ between dopamine and norepinephrine was evaluated using two-way ANOVA with Bonferroni post-tests used to correct for multiple comparisons. Statistical analysis employed GraphPad Software version 4.0 (San Diego, CA, USA). $P<0.05$ was regarded as statistically significant. Data are represented as mean \pm s.e.m. 


\section{Results}

\section{Depth profile of evoked catecholamine release in the BNST pathways}

The subregions of the BNST targeted in this work are quite small $(\sim 200 \mu \mathrm{m}$ across in the horizontal plane for the $d$ lBNST). However, as we showed in the $v$ BNST of anesthetized animals(18), evoked catecholamine release yields distinct responses as the position of the electrode is lowered, and these responses can be used to guide microelectrode placement. In these experiments, the detachable micromanipulator was implanted directly above the targeted region, and the electrode was lowered $4.8 \mathrm{~mm}$ below the skull surface. A bipolar stimulating electrode was implanted in the VTA/SN, the site of dopaminergic cell bodies, an area that is traversed by the ventral noradrenergic bundle (VNB), a pathway originating in the NST/VM cell groups. Thus, stimulation of this region evokes simultaneous norepinephrine and dopamine release. The carbon-fiber microelectrode was lowered in $\sim 0.15 \mathrm{~mm}$ increments, and catecholamine release was evoked at each position.

Figure 1A (left) shows the targeted track for measurements in the $v$ BNST. In freely moving animals, stimulated release above the BNST $(6.0 \mathrm{~mm})$ was not observed but as the carbon fiber reached the dorsomedial $(\mathrm{dm}) \mathrm{BNST}(6.3 \mathrm{~mm})$ a small signal was seen during the stimulation (Figure 1A, right). The cyclic voltammogram reveals that it arose from released catecholamines. With further lowering, the electrode reached the anterior commissure where stimulated release was not seen. Stimulated norepinephrine release was evoked at $7.5 \mathrm{~mm}$, the depth of the $v$ BNST. Comparison of Figure 1A with the data presented in anesthetized animals(18) the depth profiles are independent of anesthesia. While cyclic voltammograms distinguish between catecholamines and their metabolites, they cannot discern dopamine from norepinephrine(29). Thus, in our prior work we established that the predominant catecholamine in this subregion is norepinephrine based upon tissue content, Immunohistochemical results, and pharmacological results(18).

Figure 1B (left) shows the targeted track for the $d$ lBNST. Stimulated release was not seen at $4.8 \mathrm{~mm}$ but at the depth of the medial caudate putamen $(5.2 \mathrm{~mm})$ and the $d l$ BNST $(6.5 \mathrm{~mm})$ dopamine release was evoked (Figure 1B, right). If the electrode was lowered further into the anterior commissure, release was not evoked. Identical responses were obtained in anesthetized animals. Pharmacological, anatomical, and electrochemical data in the anesthetized animals established again that the predominant catecholamine detected in the $d l$ BNST was dopamine (Figure S1 in Supplement 1).

\section{Dopamine signaling in the dIBNST in response to tastants}

Once robust release sites were found in the $d l \mathrm{BNST}$, we examined the effect of palatable and aversive tastants on catecholamine release. Each naïve animal received repeated, small volume ( $3.5 \mathrm{~s}, 200 \mu \mathrm{L})$, intra-oral infusions of sucrose, then an equal number of quinine infusions. They were delivered at unpredictable times to ensure comparable novelty.

Intra-oral sucrose $(0.3 \mathrm{M})$ infusions increased extracellular dopamine concentration as shown in the average results from one animal (Figure 2A). In some trials, intra-oral sucrose infusions evoked a rapid and significant elevation in dopamine concentration that started during the infusion and then returned to baseline whereas in other trials no change was observed (examples in Figure 2B). In response to intra-oral quinine (0.001 M) infusions, however, dopamine concentrations decreased (averaged example from one animal in Figure 2C, individual trials in Figure 2D). The trial by trial variations with sucrose were not apparent when results from all animals were averaged together (Figure S2A in Supplement 1). The average dopamine concentration changes in multiple rats following each tastant are shown in Figure 3A. The average time for a $20 \mathrm{nM}$ change following initiation of infusion $\left(\mathrm{t}_{ \pm 20 \mathrm{nM}}\right)$ was $<5 \mathrm{~s}$ with both tastants (Figure 3B). Both the direction and the time course of 
the changes are similar to rapid dopamine signaling in response to these tastants in the NAc shell( $(8)$.

To ensure verification of the dopamine detected in each experiment, several experiments were undertaken. At each measurement site in the $d$ lBNST, idazoxan, an $\alpha_{2}$-adrenergic antagonist, and desipramine, a norepinephrine transporter inhibitor, did not alter the maximal electrically evoked dopamine concentration ([DA], Figure 3C) nor its time to return to half of its maximal concentration $\left(\mathrm{t}_{1 / 2}\right.$, Figure $\left.3 \mathrm{D}\right)$. In contrast, raclopride, a D2 antagonist, and GBR 12909, a dopamine transporter inhibitor, significantly increased both [DA] and $\mathrm{t}_{1 / 2}$ of evoked release at all $d l \mathrm{BNST}$ sites. Subsequently, an electrolytic lesion was made with the carbon-fiber microelectrode for histological identification (Figure S3A in Supplement 1). Taken together, the cyclic voltammograms, coupled with the histological and pharmacological results, confirmed that the signals reported from the $d l$ BNST arise from dopamine.

\section{Norepinephrine signaling in the $v B N S T$ in response to tastants}

In a different group of animals, we investigated norepinephrine responses in the $v$ BNST to the same intra-oral delivery of tastants. The responses were opposite to those observed for dopamine in the $d l$ BNST. Following sucrose infusions, the extracellular norepinephrine concentration gradually decreased (example from one animal in Figure 4A and B), whereas it increased following quinine delivery (example from the same animal in Figure 4C and D; average norepinephrine concentration changes in multiple rats following each tastant in Figure 5A). Mean norepinephrine concentration changes did not differ by trial number for either tastant (Figure S2B in Supplement 1) despite trial by trial variation (Figure 4B, D). The average $t_{ \pm 20 \mathrm{nM}}$ following tastant infusion in this region was $\sim 9 \mathrm{~s}$ (Figure $5 \mathrm{~B}$ ), values that are significantly longer than those for dopamine $\left(\mathrm{t}_{ \pm 20 \mathrm{nM}}, F_{1,21}=45.7, P<0.001\right.$, compare Figure 3B and 5B). Confirming norepinephrine detection, idazoxan and desipramine both significantly increased evoked [NE] and $\mathrm{t}_{1 / 2}$ (Figure $5 \mathrm{C}$ and $\mathrm{D}$ ). However, neither raclopride nor GBR 12909 significantly altered stimulated responses in this subregion. Again, electrode placements were electrolytically marked and histologically verified (Figure S3B in Supplement 1). The responses termed noradrenergic exclude those in which the carbon-fiber microelectrode was outside the $v$ BNST.

\section{Pharmacological effects on BNST catecholamine signaling in response to tastants}

Following pharmacological agents, the tastants were readministered in some animals. In the $d l$ BNST the dopaminergic response to sucrose was enhanced following raclopride, but little change was seen in the response to quinine (examples in Figure S4 in Supplement 1). In the $v$ BNST, the noradrenergic response to sucrose was unaffected by idazoxan, whereas it was amplified following quinine (examples in Figure S5 in Supplement 1). After administration of both idazoxan and desipramine, the noradrenergic response to quinine was increased even more. Evoked norepinephrine concentration lasted for a longer time in the $v$ BNST than the dopamine concentration in the $d$ BNST (Fig. 2 and 4), returning back to the pre-quinine basal norepinephrine level within a minute (examples in Figure S6 in Supplement 1). After administration of idazoxan and desipramine, increased norepinephrine in response to quinine lasted longer than a minute. Once again, the increased norepinephrine concentration in response to quinine clearly showed no change by trial number.

In eight recording sites, the pharmacological responses indicated that both norepinephrine and dopamine contributed to the cyclic voltammetric signal (indicated by red triangles in Figure S3 in Supplement 1). These sites were found in the border regions between the $d l \mathrm{BNST}$ and $d m \mathrm{BNST}$, and between $v \mathrm{BNST}$ and ventral pallidum. In four of these locations, the signals were too small for evaluation of tastant responses. However, in the remaining 
sites, the response to tastants was intermediate between that expected for norepinephrine and dopamine. An example set of responses at one of these sites at the boundary between $d l \mathrm{BNST}$ and $d m \mathrm{BNST}$ is shown in Figure 6. Following intra-oral sucrose there was a catecholamine concentration increase (mean in this animal of $10.1 \pm 2.3 \mathrm{nM}, \mathrm{n}=15$ trials) followed by a decrease $(-14.0 \pm 4.9 \mathrm{nM}$; Figure $6 \mathrm{~A})$ that fluctuated on a trial by trial basis (Figure 6B). Following intra-oral quinine, the tastant first infused in this animal, catecholamine(s) increased (Figure 6C and D, $20.5 \pm 5.8 \mathrm{nM}$ during 15 trials). Subsequently, the presence of both catecholamines was confirmed since the amplitude and time course of electrically evoked release was increased by administration of raclopride, and then further increased following idazoxan (Figure 6E). Following the two antagonists, intra-oral sucrose induced larger catecholamine increases $(51.9 \pm 6.8 \mathrm{nM}, P<0.0001$ relative to predrug responses) and the subsequent decline also appeared enhanced $(-28.4 \pm 4.9 \mathrm{nM}, P<0.05$ relative to predrug responses). However, intra-oral quinine after the antagonists induced a catecholamine increase that was indistinguishable from that before drugs in this region with mixed contributions. Evidently, the composite signal from norepinephrine and dopamine, although likely changed by the antagonist administration, summed to the same level.

\section{Discussion}

The data presented here provide the first subsecond measurements of catecholamines in the BNST of an ambulatory rat. These measurements reveal an unanticipated reciprocal relationship in the extracellular concentration changes of norepinephrine and dopamine in response to aversive and palatable tastants. As previously established in anesthetized animals, the signal in the $v$ BNST is primarily due to norepinephrine(18), and, as shown here, the predominant releasable catecholamine in the dlBNST is dopamine based on anatomical and pharmacological evidence. The boundaries of these two BNST subnuclei are separated by a microscopic distance $(\sim 150 \mu \mathrm{m})$. Nevertheless, the concentration changes of norepinephrine and dopamine are directly opposite and have significantly different temporal responses to the intra-oral delivery of palatable and aversive tastants. In the $d l$ BNST, dopamine changes occur during the infusion time of the tastant, decreasing in response to quinine and increasing in response to sucrose. In contrast, the norepinephrine responses in the $v$ BNST are the reciprocal, significantly lag those for dopamine, and show prolonged changes that exceed the $20 \mathrm{~s}$ measurement. Indeed, a cumulative decline in norepinephrine dialysate concentration from the NAc has been reported some 20 min after initiation of sucrose intake(30). Catecholamine responses to tastants also occur in other subregions of the BNST but, when they overlap, their individual contributions cannot be resolved (Figure 6).

The observed, opposing catecholamine-concentration changes in response to appetitive and aversive stimuli are consistent with prior single-unit recordings in regions afferent to the BNST. Noradrenergic neurons in the locus coeruleus show increased activity with a variety of stressors and during drug withdrawal $(17,31)$ and decreased firing rates in response to sucrose intake(32). In contrast, most dopaminergic neurons in the VTA show increased firing on presentation of rewarding stimuli, but diminished firing on presentation of aversive stimuli and during drug withdrawal(33-35). However, there are exceptions with a subset of dopamine neurons that are excited by noxious stimuli(36). Previous electrophysiological and neurochemical findings show that most dopamine neurons appear to encode a reward prediction-error rule(37-39), but it does not appear that norepinephrine neuron firing activity encodes an prediction error(37). Instead, norepinephrine neuronal signaling regulates attention, arousal, and memory(40). Noradrenergic neuronal activity appears to be elicited by conditioned stimuli, and tracks both the conditioned response and outcome of the action $(41,42)$. However, most of our knowledge of the function of norepinephrine neurons comes from electrophysiological studies in the LC, whereas the majority of noradrenergic input to the $v$ BNST originates from NST/VM(12). While electrophysiological recordings 
provide a general view of the activity of dopaminergic and noradrenergic neurons, they do not yield information on the specific release patterns of the catecholamines in their terminal regions. This can be a critical shortcoming in understanding neurotransmitter actions because chemical release can be regionally specific even though it originates from the same group of neurons(43).

The small volume sensed by the carbon-fiber microelectrode makes it highly sensitive to spatial fluctuations in the release from neurons. Our chemical measurements reveal that dopamine-encoded information concerning rewarding and aversive stimuli that is transmitted to the brain reward system is conveyed to the $d l$ BNST in an identical form to that previously reported for dopamine in another extended amygdala, the NAc shell(8). In both brain regions the responses show that a population of dopamine nerve terminals are excited by appetitive stimuli and silenced by aversive stimuli. The trial by trial variations of dopamine or norepinephrine concentrations for sucrose or quinine data were not apparent when results from all animals were averaged together $(P>0.05$ for sucrose and quinine, one-way repeated measures ANOVA) (Figure 2 and 4B, D). Identical fluctuations in release amplitudes from trial to trial has been also observed for dopamine concentration changes associated with repetitive responses to novel stimuli(44).

Accumulating evidence shows that different subregions of the BNST may play different or even opposing roles in integrating and processing limbic information and can either excite or inhibit HPA axis activity by neuronal modulation of the PVN $(12,45)$. This is clearly true for the two different subregions examined in this work. Both catecholamines modulate glutamatergic synaptic transmission at target neurons in the BNST, but in opposite ways. Dopamine in the $d$ lBNST increases spontaneous glutamatergic transmission(46), while in the $v$ BNST norepinephrine causes a decrease in glutamatergic transmission(47). Thus, their reciprocal responses to aversive and rewarding stimuli reinforce these actions. The anatomical connections of these neuronal circuits are arranged to strengthen this reciprocal relationship. For example, norepinephrine signaling enhances inhibition of BNST projections to VTA, an action that is expected to decrease dopaminergic signaling(48). Furthermore, norepinephrine engages a feed-forward system involving CRF that can further activate behavioral responses to stressors(31). The net result of these reciprocal actions of dopamine and norepinephrine is an excitation of the HPA axis in response to aversive stimuli and an inhibition in response to rewarding stimuli. The significance of these neurochemical signals is also suggested by the timing of their responses. The dopamine system rapidly conveys information about reward, providing this signal on a timescale needed for quick retrieval. In contrast, norepinephrine responses are delayed and prolonged, providing a signal that is suitable for maintained avoidance of aversive stimuli.

Thus, our data are consistent with the view that the BNST functions as a reward-aversion integrator, processing opposing hedonic states and influencing response outputs appropriate for survival. Anatomical and physiological data had inferred such integration in the BNST(45), and our results concerning catecholamine neurotransmission confirm these expectations. We have restricted our analysis of the responses to the $d$ lBNST and $v$ BNST because the two catecholamines give well resolved responses in these regions. However, our recordings in other regions of the BNST indicate that the level of integration is even greater in subnuclei where both neurotransmitters reside.

\section{Supplementary Material}

Refer to Web version on PubMed Central for supplementary material. 


\section{Acknowledgments}

This research was supported by NIH (NS 15841 to RMW and DA17318 to RMC and RMW). We thank Dr. Zoe McElligott for helpful comments regarding the manuscript.

\section{References}

1. Schultz W. Getting formal with dopamine and reward. Neuron. 2002; 36:241-263. [PubMed: 12383780]

2. Paton JJ, Belova MA, Morrison SE, Salzman CD. The primate amygdale represents the positive and negative value of visual stimuli during learning. Nature. 2006; 439:865-870. [PubMed: 16482160]

3. Koob GF, Volkow ND. Neurocircuitry of addiction. Neuropsychopharmacology. 2010; 35:217-238. [PubMed: 19710631]

4. Poulos AM, Ponnusamy R, Dong HW, Fanselow MS. Compensation in the neural circuitry of fear conditioning awakens learning circuits in the bed nuclei of the stria terminalis. Proc Natl Acad Sci U S A. 2010; 107:14881-14886. [PubMed: 20679237]

5. McElligott ZA, Winder DG. Modulation of glutamatergic synaptic transmission in the bed nucleus of the stria terminalis. Prog Neuropsychopharmacol Biol Psychiatry. 2009; 33:1329-1335. [PubMed: 19524008]

6. Day JJ, Roitman MF, Wightman RM, Carelli RM. Associative learning mediates dynamic shifts in dopamine signaling in the nucleus accumbens. Nat Neurosci. 2007; 10:1020-1028. [PubMed: 17603481]

7. Carelli RM, Wightman RM. Functional microcircuitry in the accumbens underlying drug addiction: insights from real-time signaling during behavior. Curr Opin Neurobiol. 2004; 14:763-768. [PubMed: 15582381]

8. Roitman MF, Wheeler RA, Wightman RM, Carelli RM. Real-time chemical responses in the nucleus accumbens differentiate rewarding and aversive stimuli. Nat Neurosci. 2008; 11:13761377. [PubMed: 18978779]

9. Davis M, Walker DL, Miles L, Grillon C. Phasic vs sustained fear in rats and humans: role of the extended amygdala in fear vs anxiety. Neuropsychopharmacology. 2010; 35:105-135. [PubMed: 19693004]

10. Cullinan WE, Herman JP, Watson SJ. Ventral subicular interaction with the hypothalamic paraventricular nucleus: evidence for a relay in the bed nucleus of the stria terminalis. J Comp Neurol. 1993; 332:1-20. [PubMed: 7685778]

11. Choi DC, Furay AR, Evanson NK, Ostrander MM, Ulrich-Lai YM, Herman JP. Bed nucleus of the stria terminalis subregions differentially regulate hypothalamic-pituitary-adrenal axis activity: implications for the integration of limbic inputs. J Neurosci. 2007; 27:2025-2034. [PubMed: 17314298]

12. Forray MI, Gysling K. Role of noradrenergic projections to the bed nucleus of the stria terminalis in the regulation of the hypothalamic-pituitary-adrenal axis. Brain Res Rev. 2004; 47:145-160. [PubMed: 15572169]

13. Hasue RH, Shammah-Lagnado SJ. Origin of the dopaminergic innervation of the central extended amygdala and accumbens shell: a combined retrograde tracing and immunohistochemical study in the rat. J Comp Neurol. 2002; 454:15-33. [PubMed: 12410615]

14. Meloni EG, Gerety LP, Knoll AT, Cohen BM, Carlezon WA Jr. Behavioral and anatomical interactions between dopamine and corticotropin-releasing factor in the rat. J Neurosci. 2006; 26:3855-3863. [PubMed: 16597740]

15. Lu J, Jhou TC, Saper CB. Identification of wake-active dopaminergic neurons in the ventral periaqueductal gray matter. J Neurosci. 2006; 26:193-202. [PubMed: 16399687]

16. Monti JM, Jantos H. The roles of dopamine and serotonin, and of their receptors, in regulating sleep and waking. Prog Brain Res. 2008; 172:625-646. [PubMed: 18772053]

17. Delfs JM, Zhu Y, Druhan JP, Aston-Jones G. Noradrenaline in the ventral forebrain is critical for opiate withdrawal-induced aversion. Nature. 2000; 403:430-434. [PubMed: 10667795] 
18. Park J, Kile BM, Wightman RM. In vivo voltammetric monitoring of norepinephrine release in the rat ventral bed nucleus of the stria terminalis and anteroventral thalamic nucleus. Eur J Neurosci. 2009; 30:2121-2133. [PubMed: 20128849]

19. Fendt M, Siegl S, Steiniger-Brach B. Noradrenaline transmission within the ventral bed nucleus of the stria terminalis is critical for fear behavior induced by trimethylthiazoline, a component of fox odor. J Neurosci. 2005; 25:5998-6004. [PubMed: 15976089]

20. Fuentealba JA, Forray MI, Gysling K. Chronic morphine treatment and withdrawal increase extracellular levels of norepinephrine in the rat bed nucleus of the stria terminalis. J Neurochem. 2000; 75:741-748. [PubMed: 10899950]

21. Wightman RM. Probing cellular chemistry in biological systems with microelectrodes. Science. 2006; 311:1570-1574. [PubMed: 16543451]

22. Wheeler RA, Twining RC, Jones JL, Slater JM, Grigson PS, Carelli RM. Behavioral and electrophysiological indices of negative affect predict cocaine self-administration. Neuron. 2008; 57:774-785. [PubMed: 18341996]

23. Roitman MF, Wheeler RA, Carelli RM. Nucleus accumbens neurons are innately tuned for rewarding and aversive taste stimuli, encode their predictors, and are linked to motor output. Neuron. 2005; 45:587-597. [PubMed: 15721244]

24. Paxinos, G.; Watson, C. The Rat Brain in Stereotaxic Coordinates. 6 ed.. New York: Academic Press; 2007.

25. Cahill PS, Walker QD, Finnegan JM, Mickelson GE, Travis ER, Wightman RM. Microelectrodes for the measurement of catecholamines in biological systems. Anal Chem. 1996; 68:3180-3186. [PubMed: 8797378]

26. Park J, Aragona BJ, Kile BM, Carelli RM, Wightman RM. In vivo voltammetric monitoring of catecholamine release in subterritories of the nucleus accumbens shell. Neuroscience. 2010; 169:132-142. [PubMed: 20451589]

27. Keithley RB, Carelli RM, Wightman RM. Rank estimation and the multivariate analysis of in vivo fast-scan cyclic voltammetric data. Anal Chem. 2010; 82:5541-5551. [PubMed: 20527815]

28. Keithley RB, Wightman RM. Assessing principal component regression prediction of neurochemicals detected with fast-scan cyclic voltammetry. ACS Chem Neurosci. 2011

29. Heien ML, Phillips PE, Stuber GD, Seipel AT, Wightman RM. Overoxidation of carbon-fiber microelectrodes enhances dopamine adsorption and increases sensitivity. Analyst. 2003; 128:1413-1419. [PubMed: 14737224]

30. Hajnal A, Norgren R. Sucrose sham feeding decreases accumbens norepinephrine in the rat. Physiol Behav. 2004; 82:43-47. [PubMed: 15234588]

31. Koob GF. Corticotropin-releasing factor, norepinephrine, and stress. Biol Psychiatry. 1999; 46:1167-1180. [PubMed: 10560023]

32. Aston-Jones G, Bloom FE. Norepinephrine-containing locus coeruleus neurons in behaving rats exhibit pronounced responses to non-noxious environmental stimuli. J Neurosci. 1981; 1:887-900. [PubMed: 7346593]

33. Schultz W. Predictive reward signal of dopamine neurons. J Neurophysiol. 1998; 80:1-27. [PubMed: 9658025]

34. Ungless MA, Magill PJ, Bolam JP. Uniform inhibition of dopamine neurons in the ventral tegmental area by aversive stimuli. Science. 2004; 303:2040-2042. [PubMed: 15044807]

35. Diana M, Pistis M, Muntoni A, Gessa G. Profound decrease of mesolimbic dopaminergic neuronal activity in morphine withdrawn rats. J Pharmacol Exp Ther. 1995; 272:781-785. [PubMed: 7853194]

36. Brischoux F, Chakraborty S, Brierley DI, Ungless MA. Phasic excitation of dopamine neurons in ventral VTA by noxious stimuli. Proc Natl Acad Sci U S A. 2009; 106:4894-4899. [PubMed: 19261850]

37. Schultz W, Dickinson A. Neuronal coding of prediction errors. Annu Rev Neurosci. 2000; 23:473500. [PubMed: 10845072]

38. Day JJ, Roitman MF, Wightman RM, Carelli RM. Associative learning mediates dynamic shifts in dopamine signaling in the nucleus accumbens. Nat Neurosci. 2007; 10:1020-1028. [PubMed: 17603481] 
39. Schultz W, Dayan P, Montague PR. A neural substrate of prediction and reward. Science. 1997; 275:1593-1599. [PubMed: 9054347]

40. Aston-Jones G, Cohen JD. An integrative theory of locus coeruleus-norepinephrine function: adaptive gain and optimal performance. Annu Rev Neurosci. 2005; 28:403-450. [PubMed: 16022602]

41. Bouret S, Richmond BJ. Relation of locus coeruleus neurons in monkeys to Pavlovian and operant behaviors. J Neurophysiol. 2009; 101:898-911. [PubMed: 19091919]

42. Clayton EC, Rajkowski J, Cohen JD, Aston-Jones G. Phasic activation of monkey locus ceruleus neurons by simple decisions in a forced-choice task. J Neurosci. 2004; 24:9914-9920. [PubMed: 15525776]

43. Owesson-White CA, Ariansen J, Stuber GD, Cleaveland NA, Cheer JF, Wightman RM, et al. Neural encoding of cocaine-seeking behavior is coincident with phasic dopamine release in the accumbens core and shell. Eur J Neurosci. 2009; 30:1117-1127. [PubMed: 19735286]

44. Owesson-White CA, Cheer JF, Beyene M, Carelli RM, Wightman RM. Dynamic changes in accumbens dopamine correlate with learning during intracranial self-stimulation. Proc Natl Acad Sci U S A. 2008; 105:11957-11962. [PubMed: 18689678]

45. Ulrich-Lai YM, Herman JP. Neural regulation of endocrine and autonomic stress responses. Nat Rev Neurosci. 2009; 10:397-409. [PubMed: 19469025]

46. Kash TL, Nobis WP, Matthews RT, Winder DG. Dopamine enhances fast excitatory synaptic transmission in the extended amygdala by a CRF-R1-dependent process. J Neurosci. 2008; 28:13856-13865. [PubMed: 19091975]

47. Egli RE, Kash TL, Choo K, Savchenko V, Matthews RT, Blakely RD, et al. Norepinephrine modulates glutamatergic transmission in the bed nucleus of the stria terminalis. Neuropsychopharmacology. 2005; 30:657-668. [PubMed: 15602500]

48. Dumont EC, Williams JT. Noradrenaline triggers GABAA inhibition of bed nucleus of the stria terminalis neurons projecting to the ventral tegmental area. J Neurosci. 2004; 24:8198-8204. [PubMed: 15385602] 
A

vBNST
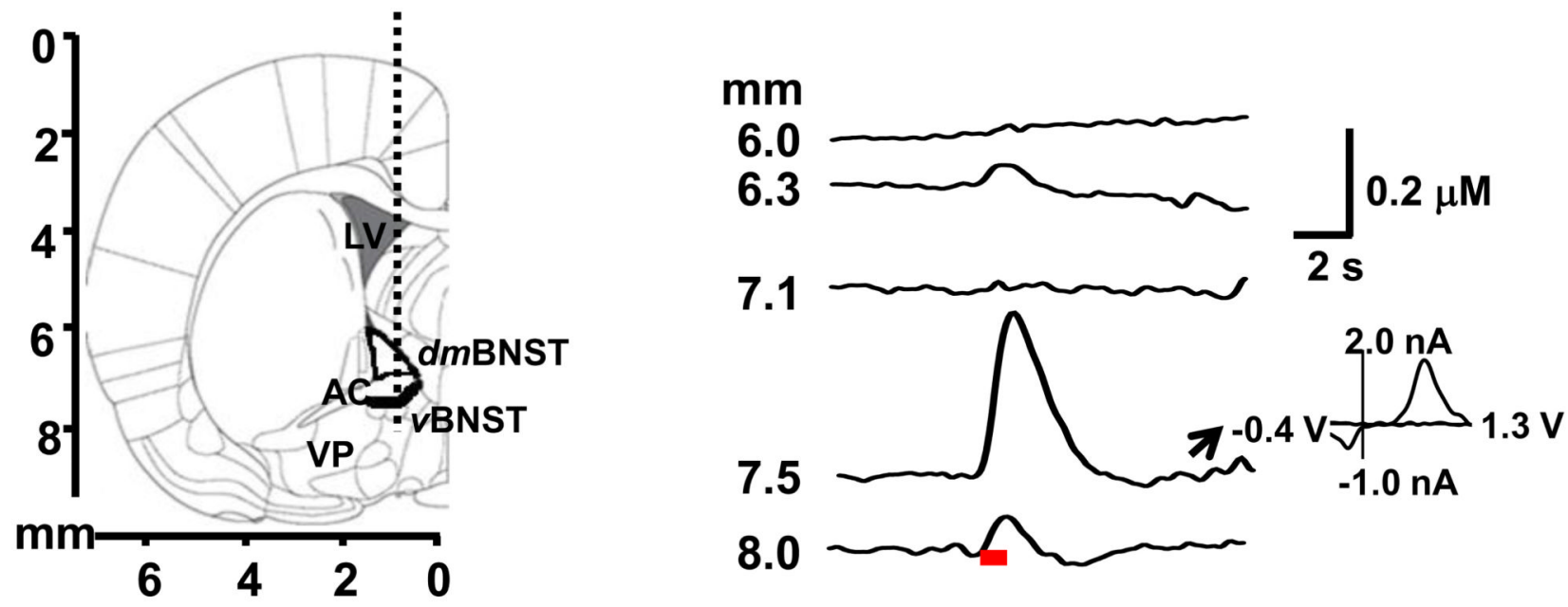

B

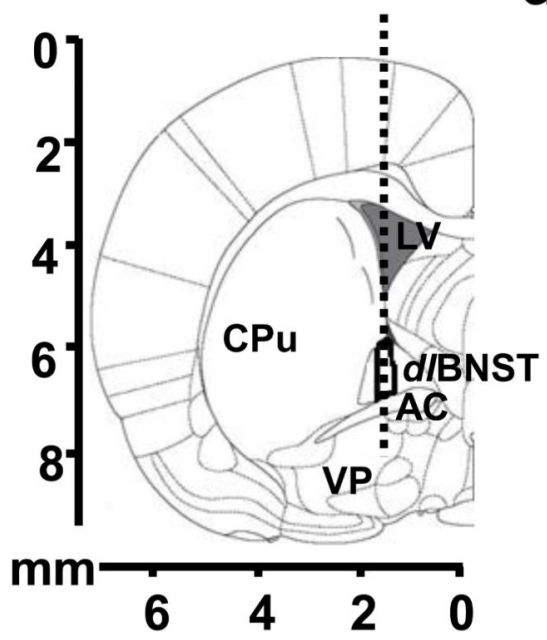

d/BNST

Figure 1.

Electrically evoked catecholamine responses in the $v$ BNST and $d l \mathrm{BNST}$. (A) and (B) (left) Diagram of the region examined at $0.0 \mathrm{~mm}$ from bregma(24). The dotted lines illustrate the approximate path of the carbon-fiber microelectrode through the $v$ BNST and $d l \mathrm{BNST}$. (A) and (B)(right) Evoked $(60 \mathrm{~Hz}, 40$ pulses, $150 \mu \mathrm{A})$ catecholamine concentrations recorded at the depth indicated. The red bars under the current trace show the electrical stimulation time. Inset: background-subtracted cyclic voltammogram measured during the indicated trace. Abbreviations: $\mathrm{CPu}$, caudate-putamen; $\mathrm{AC}$, anterior commissure; $d m \mathrm{BNST}$, dorsomedial bed nucleus of the stria terminalis; VP, ventral pallidum; LV, lateral ventricle. 


\section{d/BNST}
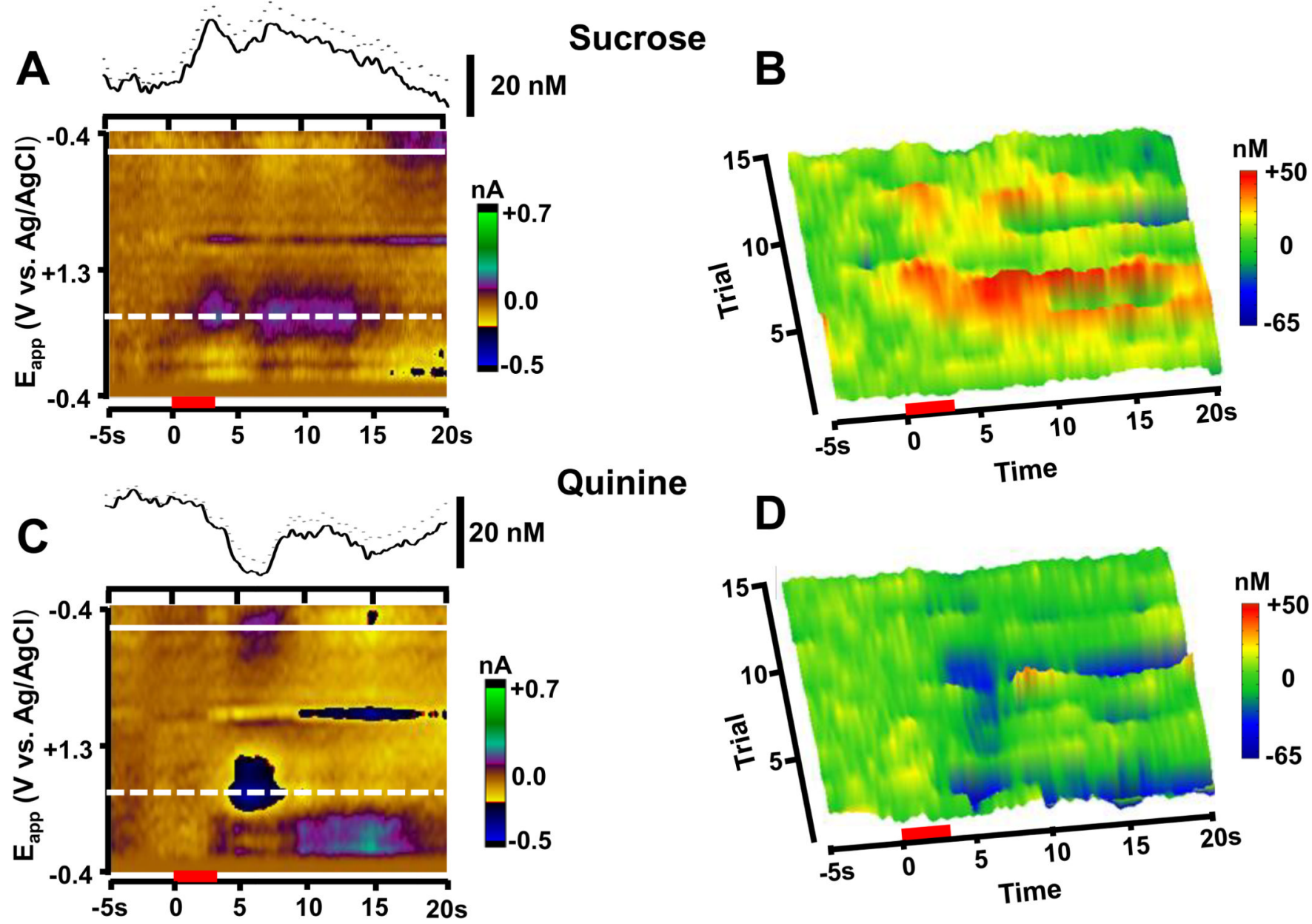

Figure 2.

Dopamine signaling in the $d l \mathrm{BNST}$ in response to palatable and aversive tastants. (A) Intraoral infusions of sucrose increase dopamine release. The upper trace is the average dopamine concentration change over 15 trials in response to intraoral sucrose infusions in a single animal (infusions during the red bar). The color plot shows the averaged cyclic voltammograms collected during the 15 trials. Catecholamine concentration changes are apparent in the color plots at the potential for its oxidation $(\sim+0.65 \mathrm{~V}$, dotted white line $)$ and its reduction ( $-0.2 \mathrm{~V}$, solid white line). (B) Trial-by-trial changes of dopamine concentration from the animal shown in (A) in response to intra-oral sucrose infusion. (C) Upper trace is the average dopamine concentration change over 15 trials in response to intraoral infusions of quinine in a single animal (infusions during the red bar). The color plot shows the average of all of the cyclic voltammograms collected during the 15 trials in this animal. (D) Trial-by-trial changes of dopamine concentration from the animal shown in (C) in response to intraoral infusions of quinine. In $(\mathrm{A})$ and $(\mathrm{C})$ the mean is given by the solid lines and \pm s.e.m. is given by the dotted lines. 


\section{dIBNST}
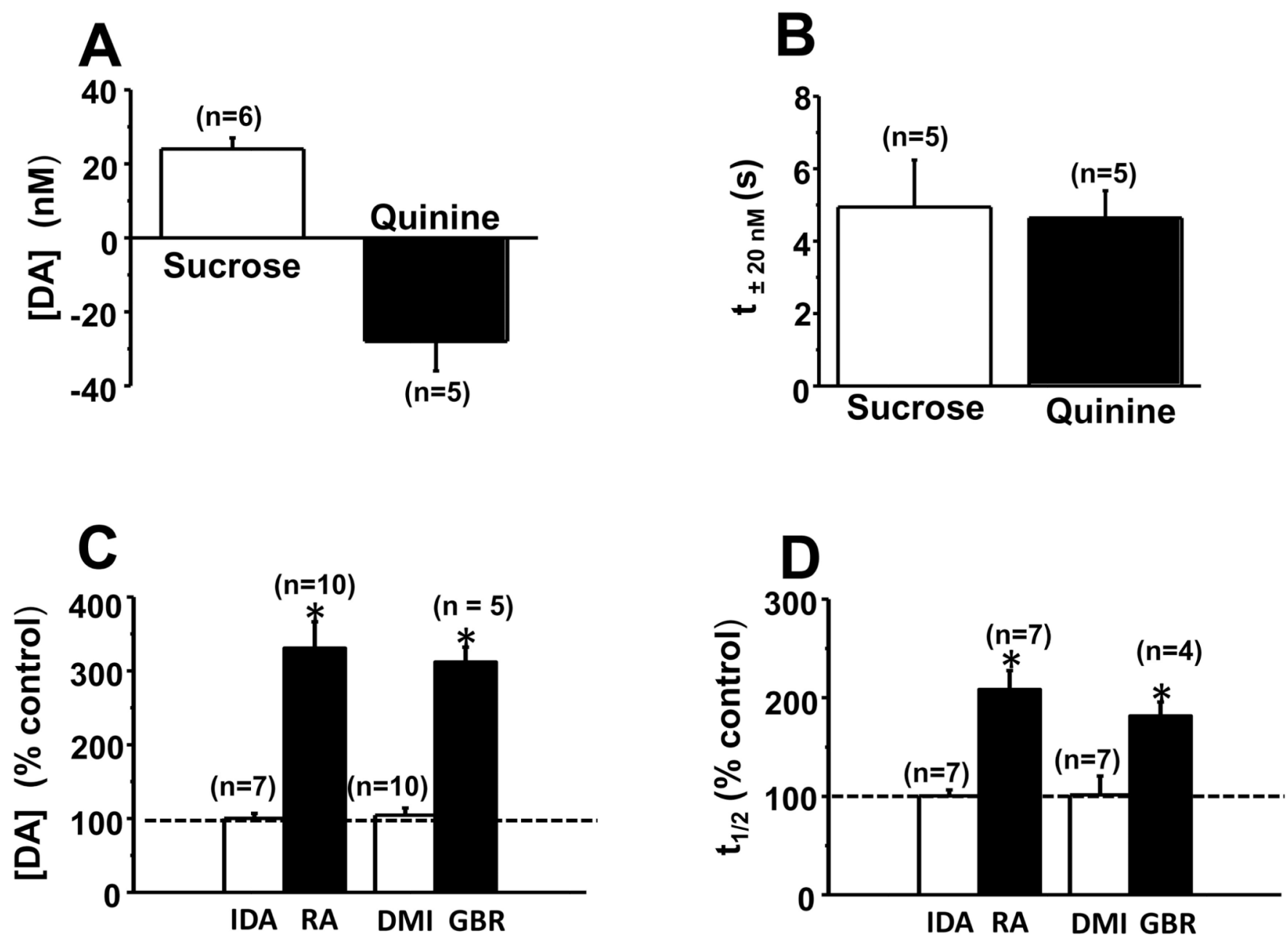

Figure 3.

Average concentration change and time course for dopamine in the $d l$ BNST. (A) Maximal dopamine concentration change measured in response to infused tastants $(P<0.005$ for sucrose, $P<0.01$ for quinine). (B) Time for dopamine to change by $20 \mathrm{nM}\left(\mathrm{t}_{ \pm 20 \mathrm{nM}}\right)$ after initiation of tastant infusion. (C, D) Effect of idazoxan (IDA, $5 \mathrm{mg} / \mathrm{kg}$ ), desipramine (DMI, $15 \mathrm{mg} / \mathrm{kg}$ ), raclopride (RA, $2 \mathrm{mg} / \mathrm{kg}$ ) and GBR 12909 (GBR, $15 \mathrm{mg} / \mathrm{kg}$ ) on electrically evoked dopamine release. (C) Maximal dopamine concentration ([DA]) and (D) time to clear the released dopamine to half of its maximal concentration $\left(\mathrm{t}_{1 / 2}\right) . *$ Indicates significantly different from control values $(P<0.05)$. 


\section{vBNST}

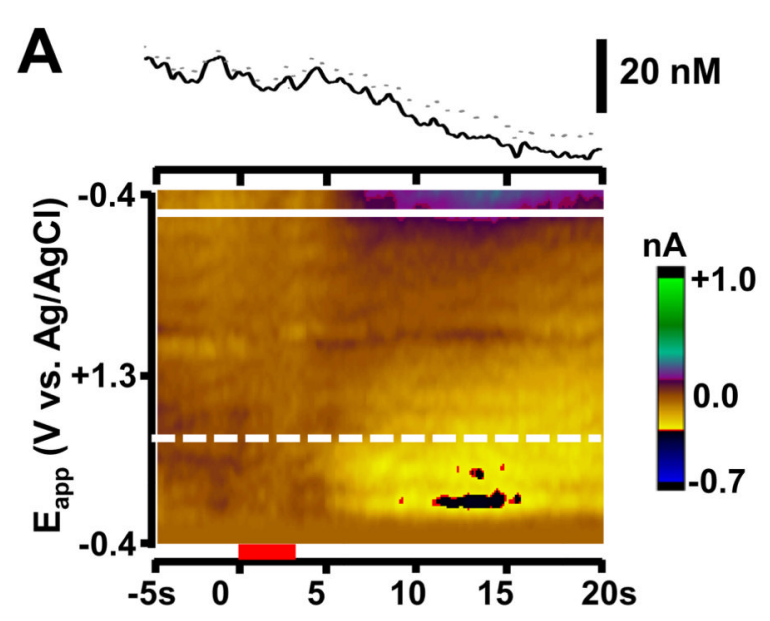

Sucrose
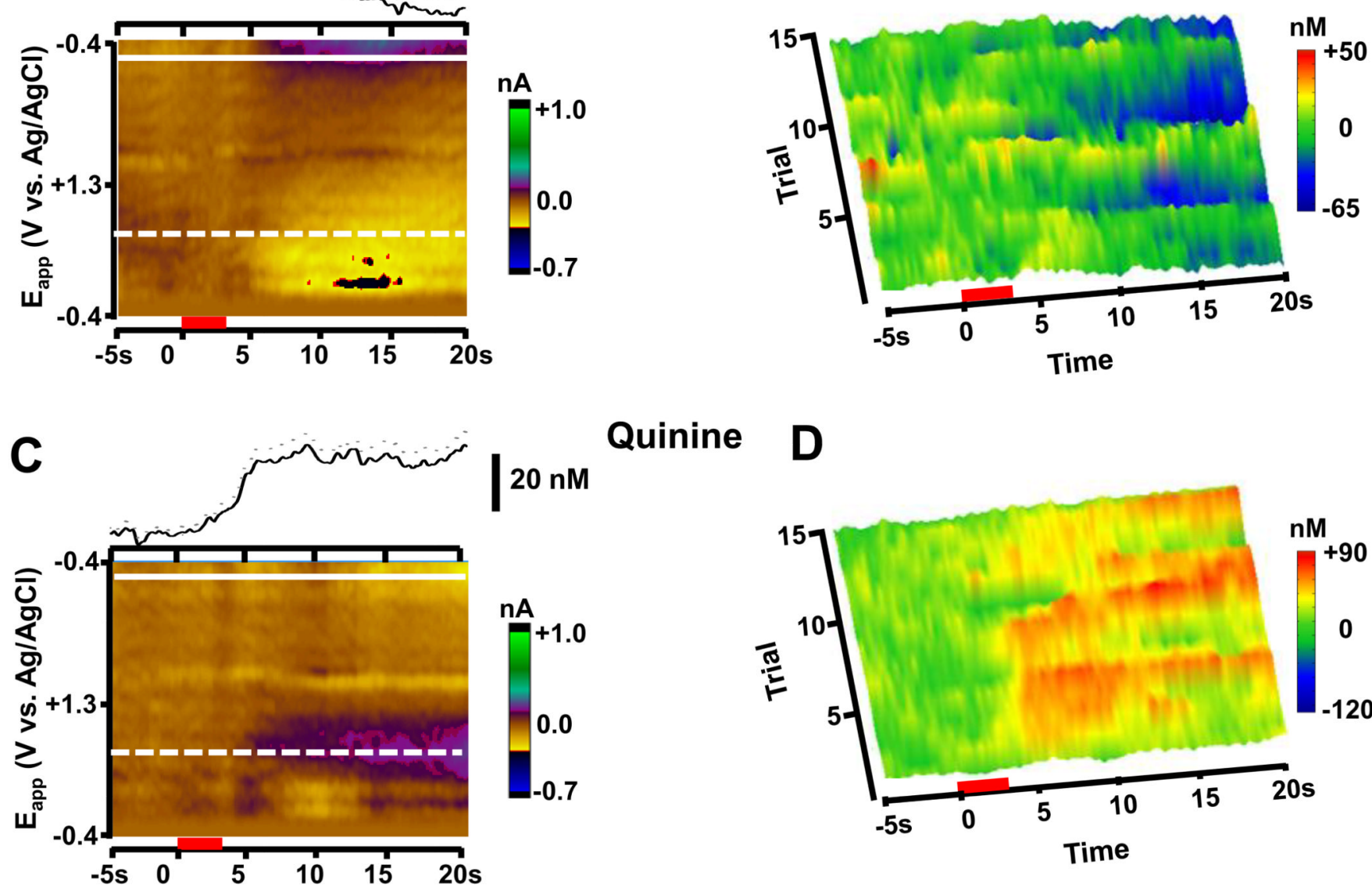

\section{Quinine}

Figure 4.

Norepinephrine signaling in the $v$ BNST in response to palatable and aversive tastants in a single animal. (A) Intra-oral infusions of sucrose decrease norepinephrine release. The upper trace is the average norepinephrine concentration change over 15 trials in response to intraoral sucrose infusions in a single animal (infusions during the red bar). The color plot shows the averaged cyclic voltammograms collected during the 15 trials. White lines are as in Figure 2(A). (B) Trial-by-trial changes of norepinephrine concentration from the animal shown in (A) in response to intra-oral sucrose infusion. (C) Upper trace is the average norepinephrine concentration change over 15 trials in response to intra-oral infusions of quinine in a single animal (infusions during the red bar). The color plot shows the average of all of the cyclic voltammograms collected during the 15 trials in this animal. (D) Trial-bytrial changes of norepinephrine concentration from the animal shown in $(C)$ in response to intra-oral infusions of quinine. In (A) and (C) the mean is given by the solid lines and \pm s.e.m. is given by the dotted lines. 

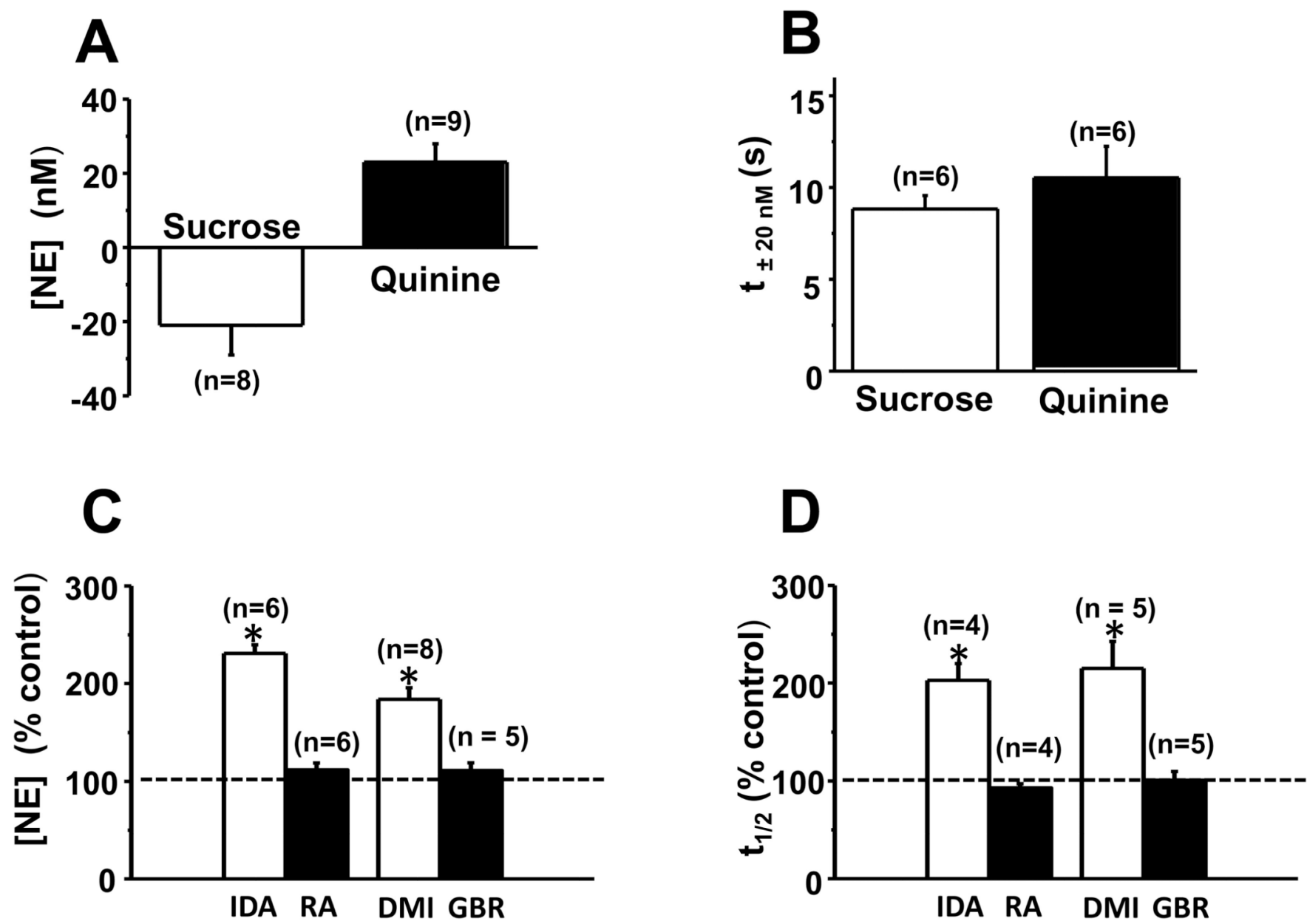

Figure 5.

Average concentration change and time course for norepinephrine in the $v$ BNST. (A) Maximal norepinephrine concentration change measured in response to infused tastants ( $p<$ 0.0001 for sucrose, $P<0.0001$ for quinine). (B) Time for $20 \mathrm{nM}$ norepinephrine changes to occur $\left(\mathrm{t}_{ \pm 20 \mathrm{nM}}\right)$ after initiation of tastant infusion. (C, D) Effect of idazoxan (IDA, $5 \mathrm{mg} / \mathrm{kg}$ ), desipramine (DMI, $15 \mathrm{mg} / \mathrm{kg}$ ), raclopride (RA, $2 \mathrm{mg} / \mathrm{kg}$ ) and GBR 12909 (GBR, $15 \mathrm{mg} / \mathrm{kg}$ ) on electrically evoked norepinephrine release. (C) Maximal evoked norepinephrine concentration ([NE]). (D) half-decay time $\left(\mathrm{t}_{1 / 2}\right)$.

* Indicates significantly different from control values $(P<0.05)$. 

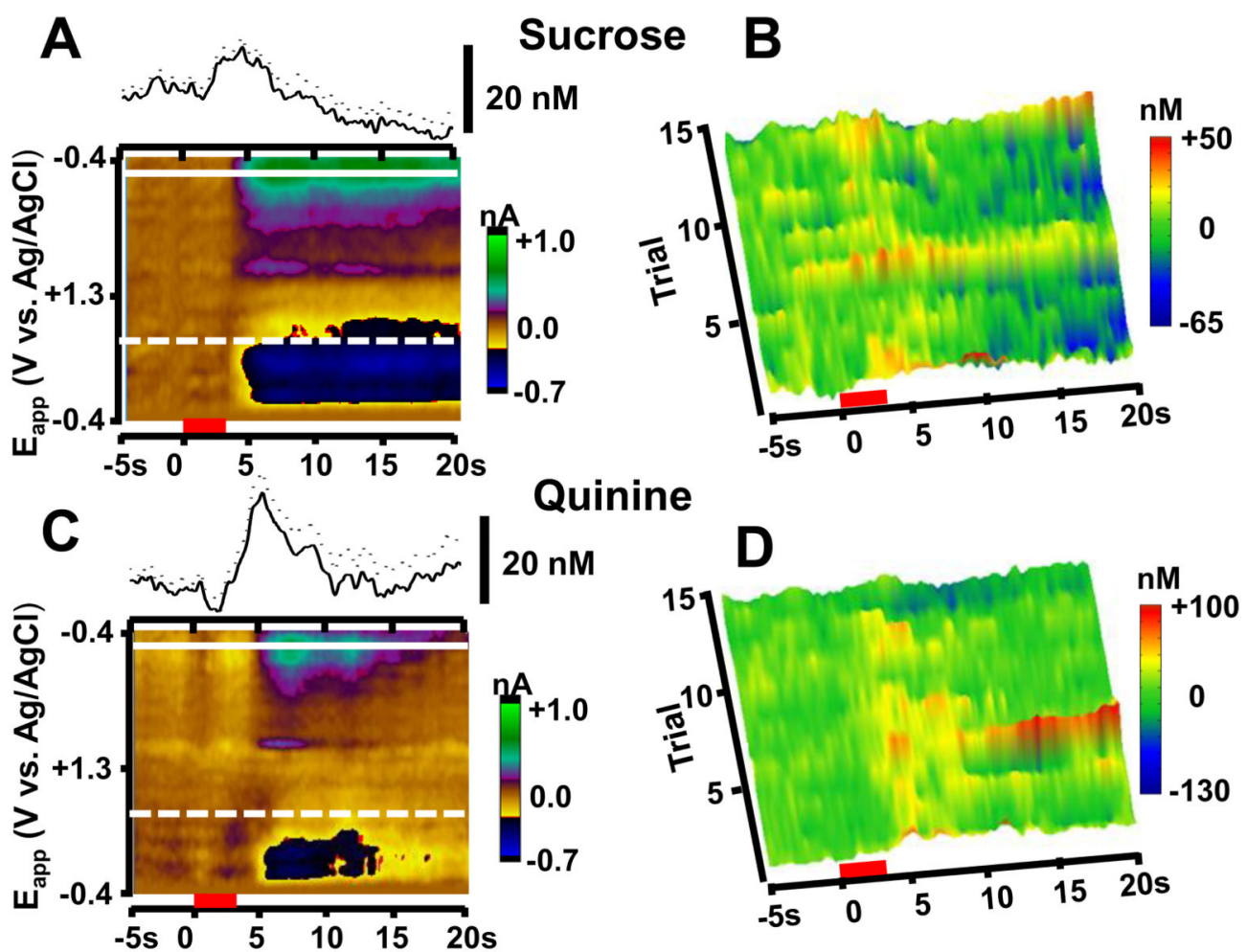

Electrical Stimulation
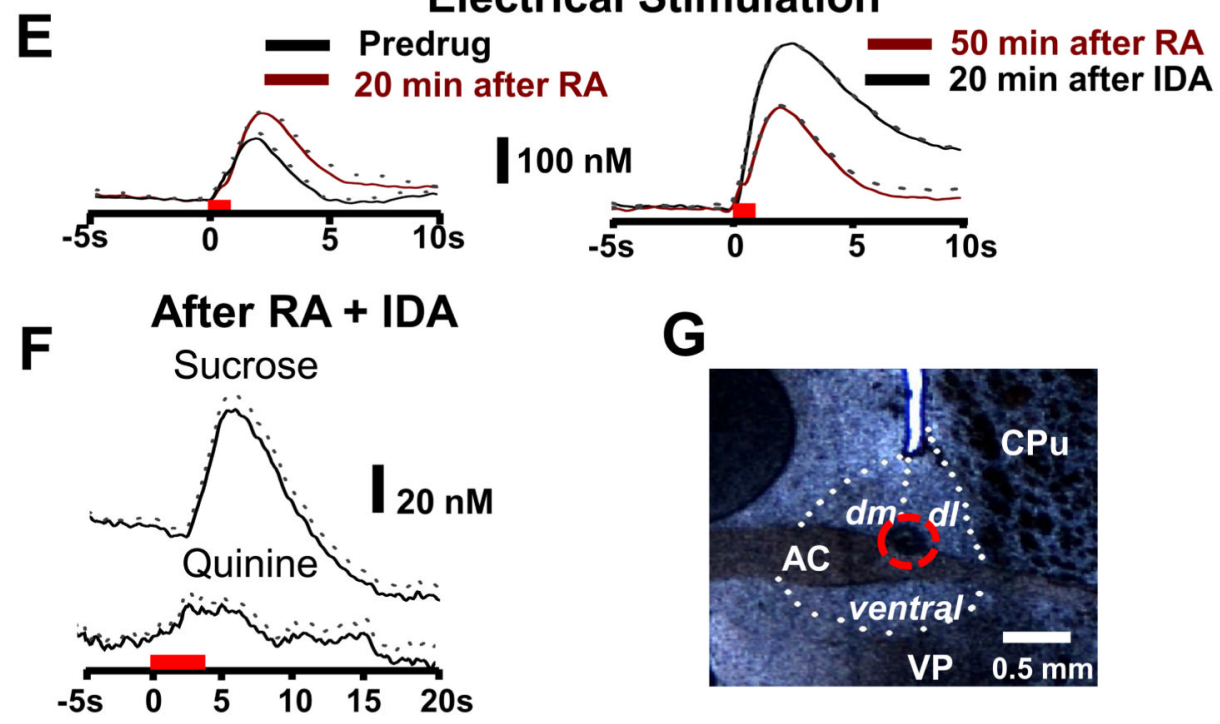

Figure 6.

Catecholamine signaling at a single location in the border of the $d l$ - and $d m \mathrm{BMST}$. (A) The upper trace is the average catecholamine concentration change over 15 trials in response to intra-oral sucrose infusions in a single animal (infusions during the red bar). The color plot shows the averaged cyclic voltammograms collected during the 15 trials. (B) Trial-by-trial changes of catecholamine concentration from the animal shown in (A) in response to intraoral sucrose infusion. (C) Upper trace is the average catecholamine concentration change over 15 trials in response to intra-oral infusions of quinine in a single animal (infusions during the red bar). The color plot shows the average of all of the cyclic voltammograms collected during the 15 trials in this animal. (D) Trial-by-trial changes of dopamine 
concentration from the animal shown in $(\mathrm{C})$ in response to intra-oral infusions of quinine. In (A) and (C) the mean is given by the solid lines and \pm s.e.m. is given by the dotted lines. (E) Responses in this location to electrical stimulation before and after administration of the RA, (predrug $[\mathrm{CA}]=167 \pm 7 \mathrm{nM}, 20 \mathrm{~min}$ post $\mathrm{RA}[\mathrm{CA}]=236 \pm 5 \mathrm{nM} P<0.005,3$ trials) and IDA ([CA] $=257 \pm 7 \mathrm{nM} 50 \mathrm{~min}$ after RA, $20 \mathrm{~min}$ after IDA [CA] $=414 \pm 4 \mathrm{nM}, P<$ $0.0001,3$ trials). (F) Average concentration traces (mean \pm s.e.m. denoted by solid and broken lines, respectively) following intra-oral sucrose (upper, $\mathrm{n}=18$ infusions) and quinine (lower, $\mathrm{n}=14$ infusions) after administration of RA and IDA. (G) An electrolytic lesion (denoted by broken red circle) in the BNST at the site where these recordings were made. Abbreviations: $\mathrm{CPu}$, caudate-putamen; $\mathrm{AC}$, anterior commissure; VP, ventral pallidum; $\mathrm{LV}$, lateral ventricle; $\mathrm{dm}$, dorsomedial bed nucleus of the stria terminalis; dl, dorsolateral bed nucleus of the stria terminalis. 